\title{
ESTUDO EXPLORATÓRIO SOBRE A REDUÇÃO DOS OLIGOSSACARÍDEOS EM FEIJÃO PRETO ATRAVÉS DA GERMINAÇÃO E TRITURAÇÃOO DOS GRÃOS E SEUS EFEITOS SOBRE A PALATABILIDADE ${ }^{1}$

\author{
EXPLORATORY STUDY ON THE REDUCTION OF OLIGOSACARIDES IN \\ BLACK BEANS THROUGH GERMINATION AND CRUSHING GRAINS \\ AND THEIR EFFECTS ON PALATABILITY
}

\author{
Ana Paula Brandão Piloni e William Leonardo da Silva ${ }^{3}$
}

\section{RESUMO}

O feijão preto (Phaseolus vulgaris) faz parte dos alimentos tradicionais consumidos na dieta da população brasileira, constituindo-se de uma excelente fonte de proteína e nutrientes essenciais como ferro, cálcio, zinco, magnésio, vitaminas (principalmente do complexo B), carboidratos e fibras. Entretanto, o feijão apresenta na sua composição oligossacarídeos da família estaquiose e rafinose, os quais prejudicam a digestibilidade do mesmo, causando os desconfortos gastrointestinais (flatulência), geralmente atribuídos a ausência da enzima $\alpha$-galactosidase. Assim, este trabalho tem como objetivo a aplicação do processo de germinação dos grãos de feijão, a fim de reduzir os teores destes oligossacarídeos e, assim reduzir os desconfortos intestinais. A análise sensorial foi realizada com objetivo de avaliar a efetividade do processo de germinação dos grãos de feijão, conforme o relato de um provador, após ingestão de amostras com os grãos germinados. A germinação ocorreu em 37 horas com 600 gramas de feijão, congelados por 3 dias, descongelados por 3h, cozidos em panela de pressão por 30 minutos, triturados em liquidificador, desidratados em estufa e, por fim triturados formando o pó desejado. Por conseguinte, o rendimento obtido foi de $53,83 \%$ do pó de feijão desidratado, demonstrando uma efetividade do processo de germinação.

Palavras-chave: Phaseolus vulgaris, $\alpha$-galactosidase, desconfortos intestinais.

\section{ABSTRACT}

Black beans (Phaseolus vulgaris) are part of traditional food consumed in the diet of the Brazilian population, constituting an excellent source of protein and essential nutrients such as iron, calcium, zinc, magnesium, vitamins (mainly from B complex), carbohydrates and fiber. However, beans present in their composition oligosaccharides of the family stachyose and raffinose, which impair their digestibility, causing discomfort (flatulencies), usually attributed to the absence of the a-galactosidase enzyme. Thus, this work aims at applying the process of germination of the bean grains, in order to reduce the contents of these oligosaccharides and, thus reduce the intestinal discomfort. The sensory analysis was carried out to evaluate the effectiveness of the germination process of the bean grains, according to the reports of a taster, after ingestion of samples with the germinated grains. The germination occurred in 37 hours with 600 grams of beans, frozen for 3 days, thawed for 3 hours, cooked in a pressure cooker for 30 minutes, crushed in a blender, dehydrated in a greenhouse and, finally crushed to form the desired powder. Therefore, the yield obtained was $53.83 \%$ of the dehydrated bean powder and the sensorial

\footnotetext{
${ }^{1}$ Trabalho Final de Graduação II (TFG II)

${ }^{2}$ Acadêmica do Curso de Engenharia Química- Universidade Franciscana. E-mail: paulapiloni@yahoo.com.br

${ }^{3}$ Orientador - Professor do Curso de Engenharia Química - Universidade Franciscana. E-mail: w.silva@unifra.br.
} 
analysis indicated an amelioration of the intestinal discomforts, demonstrating an effectiveness of the germination process.

Keywords: Phaseolus vulgaris, $\alpha$-galactosidase, intestinal disconforts.

\section{INTRODUÇÃO}

O feijão é um dos alimentos mais consumidos, cultivados e encontrados em todo território nacional. Conforme Esteves (2000), o feijão produzido na lavoura pode ser classificado em dois grupos (I e II) de acordo com a coloração do tegumento (película) do grão (KNABBEN; COSTA, 2012).

O grupo I é constituído por feijão comum de cultivares da espécie Phaseolus vulgaris (L.) que, dependendo da composição do produto, poderá ser caracterizado como feijão branco (97\% da coloração do feijão é branca), feijão preto (constituído por mais de 97\% de grãos de coloração preta), ou feijão colorido. O feijão colorido é constituído de grãos da mesma coloração, admitindo-se, no máximo, $3 \%$ de mistura de outras classes e de 10\% de mistura de outras cultivares da classe cores, desde que apresente cores contrastantes ou tamanhos diferentes. Por fim, ainda é possível classificação de "feijão misturado", caracterizado por ser um produto que não atende às especificações de nenhuma das classes anteriores (KNABBEN; COSTA, 2012; ESTEVES, 2000).

O grupo II é constituído por feijão comum de cultivares da espécie Vigna unguiculata (L.) (KNABBEN; COSTA, 2012; ESTEVES, 2000). Assim como o grupo I, neste grupo também ocorre a classificação por cores, em que é possível encontrar feijão branco ( $90 \%$ do grão com coloração branca); feijão preto (90\% do grão com coloração branca); feijão colorido (produto que contém, no mínimo, 90\% de grãos da classe cores, admitindo-se até $10 \%$ de mistura de outras cultivares da classe cores, desde que apresente cores contrastantes ou tamanhos diferentes) e, por último, feijão misturado, que apresenta menor valor agregado comparado com as demais classificações (KNABBEN; COSTA, 2012). Neste cenário, o Brasil destaca-se por ser o maior produtor e consumidor mundial de feijão preto (Phaseolus vulgaris), com cerca de 3,2 milhões de toneladas ao ano, juntamente como outras leguminosas, como lentilha, ervilha e grão-de-bico (SOCIEDADE NACIONAL DE AGRICULTURA, 2018).

Além disso, o feijão preto caracteriza-se pelo seu elevado valor nutricional, baixa concentração de gordura e considerável conteúdo de carboidratos complexos, proteínas, vitaminas do complexo B, fibras, cálcio e fibras alimentares, conforme a Tabela 1. 
Tabela 1 - Composição centesimal do feijão preto comum (Phaseolus vulgaris).

\begin{tabular}{|cc}
\hline Componentes & Quantidade $\left(\mathbf{g ~}^{\mathbf{~ 1 0 0}} \mathbf{g}^{-1}\right)$ \\
\hline Umidade & 9,4 \\
\hline Proteínas & 18,4 \\
\hline Lipídeos totais & 2,3 \\
\hline Cinzas & 0,6 \\
\hline Fibras & 4,6 \\
\hline Carboidratos & 64,7 \\
\hline Rafinose & 0,4 \\
\hline Estaquiose & 3,23 \\
\hline Verbascose & 0,12 \\
\hline Fonte: Adaptado de Oliveira e colaboradores, 2008.
\end{tabular}

Conforme a Tabela 1, o feijão preto comum apresenta em sua composição oligossacarídeos, como a rafinose e estaquiose, que são açúcares que não são digeridos pelo organismo humano e, desse modo, podem ocasionar a produção de flatulências em decorrência da falta de atividade da enzima $\alpha$-galactosidase, responsável pela hidrólise (clivagem) das ligações galactosídicas $\alpha-1-6$ no trato gastrointestinal (YAMAGUISHI, 2008; TACO, 2011; RUPÉREZ, 1998; BARAMPAMA; SIMARD, 1993). Desse modo, o acúmulo destes oligossacarídeos no intestino delgado, conduzem à digestão anaerobicamente pela flora intestinal, resultando em maior produção de gases fermentados, como o dióxido de carbono, hidrogênio e metano, afetando diretamente na diminuição do consumo de feijão pela população, pelos problemas causados com as flatulências.

Adicionalmente, as técnicas mais eficientes para a eliminação dos oligossacarídeos da família estaquiose e rafinose estão a germinação e a fermentação, devido a produção da enzima $\alpha$-galactosidase (GUIMARÃES et al., 2001). Destaca-se a técnica de germinação dos grãos do feijão, visto que proporciona a hidrólise das ligações glicosídicas entre as moléculas de $\alpha$-glicose do amido em maltose e oligossacarídeos, além da proteína vegetal em aminoácidos essenciais e não-essenciais, auxiliando na liberação da enzima $\alpha$-galactosidase, que anteriormente não estavam disponíveis (MAMBRIN et al., 2015). Além disso, o processo de germinação promove a absorção de água, aumentando o volume do grão e, assim um aumento no valor nutricional e na maior quantidade de proteínas, vitaminas e minerais (COELHO et al., 2010).

Neste contexto, o presente trabalho tem por objetivo estudar o processo de redução do teor de oligossacarídeos estaquiose e rafinose presentes no feijão preto comum, após o processo de germinação dos grãos, a fim e reduzir os desconfortos causados pelos mesmos. 


\section{MATERIAIS}

\section{MATERIAIS E EQUIPAMENTOS}

Para a redução do teor dos oligassacarídeos e o processo de germinação dos grãos foram utilizados os seguintes materiais e equipamentos, conforme Tabela 2.

Tabela 2 - Materiais e equipamentos utilizados no trabalho.

\begin{tabular}{cc}
\hline Materiais & Procedência \\
\hline Grãos de feijão preto & Comercial (Caldo Bom) \\
\hline Liquidificador & Comercial \\
\hline Balança analítica & BEL Engineering, Mark M214A, Itália \\
\hline Termômetro & Incoterm, 179410/17, Brasil \\
\hline Estufa & DeLeo, Estufa para secagem e esterilização, Brasil \\
\hline & Fonte: Construção do Autor.
\end{tabular}

\section{GERMINAÇÃO DOS GRÃOS DE FEIJÃO}

O processo de germinação dos grãos foi adaptado da literatura (ZAMBIASI, 2015) para a determinação de temperatura, tempo de germinação, massa de feijão e quantidade de água. Assim, inicialmente foram selecionados os grãos do feijão de boa qualidade, excluindo sujeiras e grãos defeituosos, e pesados (cerca de $600 \mathrm{~g}$ de grãos de feijão preto), lavados em água potável. Em seguida, os grãos foram alocados em um recipiente de vidro, previamente esterilizado com água fervente a $100{ }^{\circ} \mathrm{C}$ por 10 minutos os grãos, e passaram pelo período de molho, onde foram acrescentados 900 $\mathrm{mL}$ de água potável (temperatura de aproximadamente $22^{\circ} \mathrm{C}$ ) com circulação de ar por 13 horas, em um local fresco e protegido de luz solar. Passando o período determinado, os grãos foram novamente enxugados e lavados (600 mL de água potável por mais 12 horas), seguida de uma nova verificação de grãos defeituosos. Por fim, os mesmos foram tapados com um tecido fino pressionado por um elástico e deixado em um ângulo de aproximadamente $45^{\circ}$, com o bocal voltado para baixo em um escorredor em local fresco e protegido da luz 12 horas e, enxaguados em água corrente.

\section{PREPARO PARA O COZIMENTO DOS GRÃOS}

Posteriormente ao processo de germinação, os grãos foram congelados por 72 horas em congelador comum de geladeira. Após, foi feito realizado o descongelamento em temperatura de aproximadamente $8{ }^{\circ} \mathrm{C}$ (72 horas) e cozido em panela de pressão por 30 minutos. Por fim, os grãos foram coados com peneira doméstica, para separar os grãos do caldo, macerados e triturados juntamente com $600 \mathrm{~mL}$ de água potável em um liquidificador comum. 
Após o processo de germinação e cozimento dos grãos, iniciou-se o processo de desidratação dos mesmos, conforme adaptação da literatura (OLIVEIRA et al., 2008). Assim, inicialmente, os grãos foram alocados em uma estufa por 40 horas $\left(60-65^{\circ} \mathrm{C}\right)$, seguido de trituração (liquidificador comercial) e peneiramento (coado de malha fina), a fim de uniformizar e retirar pedaços maiores, formando o pó de feijão germinado.

\section{RESULTADOS E DISCUSSÕES}

\section{GERMINAÇÃO DOS GRÃOS DE FEIJÃO}

A Figura 1 apresenta a germinação do grão de feijão, destacando que cerca de $85 \%$ dos mesmos foram germinados, enquanto somente os grãos localizados na parte inferior não germinaram, devido ao peso dos grãos sob estes e ao excesso de umidade, impedindo a penetração do oxigênio e, assim a diminuição do processo metabólico (DE MORAES, 2007; RIBEIRO et al., 2012).

Figura 1 - Ilustração da germinação dos grãos de feijão.

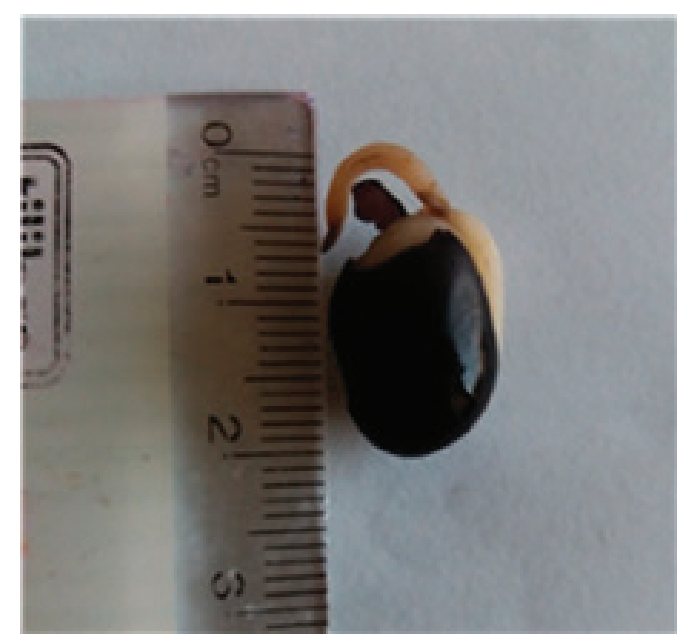

Fonte: Construção do Autor.

\section{PREPARAÇÃO DO PÓ DE FEIJÃO GERMINADO/DESIDRATADO}

O pó de feijão germinado/desidratado foi preparado após a germinação dos grãos e sua cocção (indicando uma boa maciez), seguida da trituração (formando uma pasta viscosa) (Figura 2a) e, por fim da desidratação (Figura 2b), obtendo um pó fino com boa solubilidade em água, indo ao encontro do que reportado na literatura (OLIVEIRA et al., 2008; MARTINEZ, 2011). Destaca-se que a quantidade obtida de pó de feijão foi de 323 gramas, apresentando um rendimento de 53,83 \%. 
Figura 2 - (a) Formação da pasta pós trituração dos grãos germinados e cozidos e (b) pó de feijão desidratado.

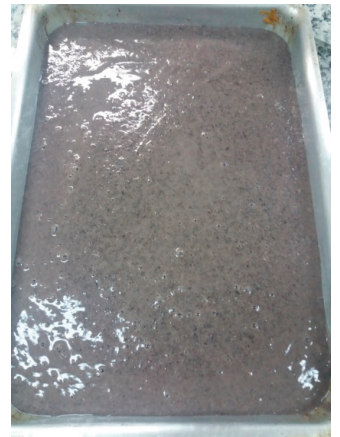

(a)

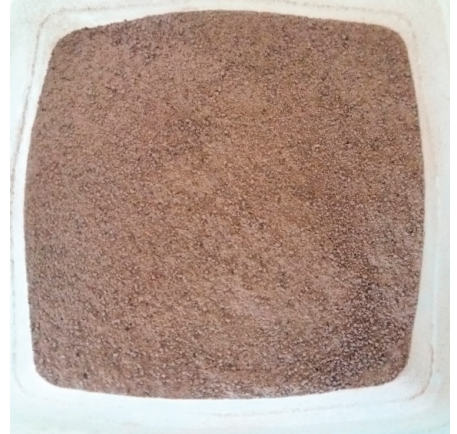

(b)

Fonte: Construção do Autor.

\section{CONCLUSÕES}

Com bases nos resultados preliminares apresentados, pode-se verificar que o processo de germinação dos grãos de feijão se apresentou efetivo quanto a redução dos desconfortos intestinais causados pela presença dos oligossacarídeos estaquiose e rafinose, conforme análise sensorial. Além disso, o rendimento obtido do pó de feijão germinado e desidratado foi de 53,83 \% em relação à quantidade inicial de grãos, enquanto cerca de $85 \%$ dos grãos foram germinados. Os autores gostariam de destacar que novas amostras do pó desidratado/germinado de feijão será produzido, bem como uma nova análise sensorial será aplicada em um número maior de provadores.

\section{REFERÊNCIAS}

BARAMPAMA, Z.; SIMARD, R.E. Nutrient composition, protein quality and antinutritional factors of some varieties of dry beans (Phaseolus vulgaris) grown in Burundi. Food Chemistry, v. 47, p. 159-167, 1993.

COELHO, C.M.M.; et al. Potencial fisiológico em sementes de cultivares de feijão crioulo (Phaseolus vulgaris L.). Revista Brasileira de Sementes, v. 32, p. 97-105, 2010.

DE MORAES, J.V. Morfologia e germinação de sementes de Poecilanthe parviflora Bentham (FABACEAE - FABOIDEAE). 2007. 88p. Dissertação (Mestrado em Agronomia) - Programa de Pós-Graduação em Agronomia, Faculdade de Ciências Agrárias e Veterinárias, Jaboticabal, São Paulo, 2007. 
ESTEVES, A.M. Composição química e enzimática de seis linhagens de feijão (Phaseolus vulgaris L.). 2000. 55p. Dissertação (Mestrado em Ciência dos Alimentos) - Curso de Pós-Graduação em Ciência dos Alimentos, Universidade Federal de Lavras, Minas Gerais, 2000.

GUIMARÃES, V.M.; et al. Characterization of $\alpha$-galactosidases from germinating soybean seed and their use for hydrolyses of oligosaccharides. Phytochemistry, v. 58, p. 67-73, 2001.

KNABBEN, C. C.; COSTA, J. S. Manual de classificação do feijão: instrução normativa n. 12, de 28 de março de 2008. Embrapa Arroz e Feijão-Fôlder/Folheto/Cartilha (INFOTECA-E), 2012.

MAMBRIN, R.B.; et al. Seleção de linhagens de feijão com base no padrão e na qualidade de sementes. Revista Caatinga, v. 28, p. 147-156, 2015.

MARTINEZ, P.C.C. Efeito do processo de germinação sobre as características nutricionais do feijão. 2011. 220p. Dissertação (Mestrado em Ciência) - Programa de Pós-Graduação em Ciência e Tecnologia de Alimentos), Universidade de São Paulo, São Paulo, 2011.

MEILGAARD, M.; et al. Sensory evaluation techniques. 3. ed. London: CRC Press, 1999.

OLIVEIRA, V.R.; et al. Qualidade nutricional e microbiológica de feijão (Phaseolus vulgaris L.) cozido com ou sem água de maceração. Ciência e Agrotecnoloiga, v. 32, p. 1912-1918, 2008.

RIBEIRO, C.A.D.; et al. Fatores que afetam a germinação das sementes e a biomassa de plântulas de Tabebuia heptaphylla. Floresta, v. 42, p. 161-168, 2012

RUPÉREZ, P.Z. Oligosaccharides in raw and processed legumes. Zeitschrift für Lebensmittel-Untersuchung und Forschung, v. 206, p. 130-133, 1998.

SOCIEDAdE NACIONAL DE AGRICULTURA. Ministério da Agricultura, Pecuária e Abastecimento. Gestão e Experiência a Serviços do Agronegócio - Rio de Janeiro: 2018. Disponível em: http://www.sna.agr.br/. Acesso em: mai. 2018.

TACO. Tabela Brasileira de Composição de Alimentos, 4. ed. Campinas: UNICAMP, 2011.

XIAOLI, X.; et al. Determination of oligosaccharide contents in 19 cultivars of chickpea (Cicer arietinum L.) seeds by high performance liquid chromatography. Food Chemistry, v. 111, p. 215-219, 2008. 
YAMAGUISHI, C.T. Processo biotecnológico para a produção de feijão desidratado com baixo teor de oligossacarídeos da Família Rafinose. 2008. 148p. Dissertação (Mestrado em Processos Biotecnológicos) - Programa de Pós-Graduação em Processos Biotecnológicos, Universidade Federal do Paraná, Curitiba, 2008.

ZAMBIASI, C.A. Qualidade de grãos de feijão armazenados em diferentes condições de temperatura. 2015. 91p. Tese (Doutorado em Engenharia Agrícola) - Programa de Pós-Graduação em Engenharia Agrícola, Universidade Federal de Viçosa, Minas Gerais, 2015. 